\title{
Progress in the Search for Specific Brain Systems That Mediate the Symptoms of obsessive-Compulsive Disorder
}

\section{REFERENCES}

1. Brody AL, Saxena S. Brain imaging in obsessive-compulsive disorder: Evidence for the involvement of frontal-subcortical circuitry in the mediation of symptomatology. CNS Spectrums. 1996;1:27-41.

2. Thompson JM, Baxter LR, Schwartz JM. Freud, obsessive-compulsive disorder and neurobiology. Psychoanalysis and Contemporary Thought. 1992;15:483-505.

3. Schilder PL. The organic background of obsessions and compulsions. Am J Psychiatry. 1938;94:1397-1414.

4. Freud S. Project for a scientific psychology. In: Strachey J, ed. The Standard Edition of the Complete Psychological Works of Sigmund Freud, vol 1. London: Hogarth Press; 1964: 283-294.

5. Baxter LR, Saxena S, Brody AL, et al. Brain mediation of obsessive-compulsive disorder symptoms: Evidence from functional brain imaging studies in the human and nonhuman primate. Seminars in Clinical Neuropsychiatry. 1996;1:32-47.

6. Freud $S$. The question of lay analysis (1926). In: Strachey J, ed. The Standard Edition of the Complete Psychological works of Sigmund Freud, vol 20. London: Hogarth Press; 1964:231.

7. Parent A. Comparative Neurobiology of the Basal Ganglia, New York: John Wiley and Sons; 1986.

8. Dodman NH, Olivier B. In search of animal models for obsessive-compulsive disorder. CNS Spectrums. 1996; 2:10-14.

9. Myers JK, Weissman MM, Tischler GL, et al. Six-month prevalence of psychiatric disorders in three communities. Arch Gen Psychiatry. 1984; 41:959-967.
The first issue of CNS Spectrums featured a review ${ }^{1}$ by Drs. Arthur Brody and Sanjaya Saxena of the last decade's brain imaging findings in obsessive-compulsive disorder (OCD). Based largely on the studies they review, many investigators have speculated about a neuroanatomical localization for brain functions that may be involved in the mediation of OCD's symptoms. Given the consistency of these findings, and the number of scientists who have arrived at similar conclusions independently, if the brain systems described by these two authors are not the actual site of causative pathology, it seems that they must at least be along a final common neural pathway that enables OCD's behavioral expression.

Although Sigmund Freud acknowledged that the symptoms of this malady must have a "constitutional basis," ${ }^{2}$ and the first scholarly reports linking OCD symptoms with pathology in specific brain regions - the basal gangliaappeared almost 60 years ago, ${ }^{3}$ it is still remarkable to me, a physician trained in the 1970s, how quickly this classical "neurosis" has moved from etiologic speculations centered on toilet training to explanations based on functional neuroanatomy. Indeed, as Brody and Saxena's article illustrates, the increasing level of our understanding of corticobasal ganglionicthalamic circuitry in the mediation of OCD symptoms is beginning to rival medical understanding of other neuropsychiatric diseases of the basal ganglia, such as Parkinson's and Huntington's diseases. Freud, originally a neuropathologist-and a man who spent 3 years of his life trying to explain neurotic behavior based on what was known about brain function in the late 19 th century ${ }^{2.4}$-would certainly have seen the present state of knowledge about OCD that has derived from drug challenge, biochemical, and imaging studies ${ }^{5}$ as a vindication of his 70-year-old prediction: "We may look forward to a day when paths of knowledge and, let us hope, of influence will be opened up, leading from organic biology and chemistry to the field of neurotic phenomena...." 5

But where do such endeavors go from here? Although there now seems to be a wealth of
BY LEWIS R. BAXTER, JR., MD

evidence for the involvement of corticobasal ganglionic-thalamic circuits in OCD, this information does not tell us anything about the neurochemical specifics of the disease. Neuroimaging studies to date have told us where to look, but now new methods need to be applied to dissect the specifics of the neurochemical and genetic workings in the brain regions to show how they result in symptom expression.

Besides research with human subjects, this task would seem ripe for the application of animal and single cell basic science techniques, since it is known that even the specifics of function in these brain circuits are very similar to the human in all other terrestrial vertebrates. ${ }^{?}$ This issue of CNS Spectrums reviews animal models of OCD, ${ }^{8}$ but even if there were no true, naturalistic animal models of human OCD (a prospect I think unlikely, given the ethology of such behaviors), the more we can learn about the "switches and rheostats" of homologous animal behaviors as they operate in these circuits, the closer we will be to understanding the brain mediation of OCD.

At this time, a concerted effort using both clinical and basic science strategies, and employing the methods of molecular genetics, immunology, neurochemistry, and neuroimaging, seems fully justified-and likely to yield progress similar to that which has resulted from substantial funding for research on two other neuropsychiatric illnesses of the basal ganglia, Huntington's and Parkinson's diseases. Given that severe forms of OCD afflict at least 5 million people in the United States at any one time, ${ }^{9}$ funding agencies like the National Institutes of Health should adjust their priorities to take advantage of opportunities to understand and conquer the tortuous affliction of OCD. CNS

Dr. Baxter is Kathy Ireland Professor of Psychiatric Research, director, behavioral neurobiology, and vice-chair for research, University of Alabama at Birmingham Department of Psychiatry and Behavioral Neurobiology, and professor of psychiatry and pharmacology at the UCLA School of Medicine. 